\title{
Clinical significance of microRNA-34b expression in pediatric acute leukemia
}

\author{
LAN CAO, NA WANG, JIAN PAN, SHAOYAN HU, WENLI ZHAO, \\ HAILONG HE, YI WANG, GUIXIONG GU and YIHUAN CHAI
}

\begin{abstract}
Department of Hematology and Oncology, Children's Hospital of Soochow University, Suzhou, Jiangsu 215003, P.R. China
\end{abstract}
Received February 17, 2015; Accepted December 3, 2015

DOI: $10.3892 / \mathrm{mmr} .2016 .4876$

\begin{abstract}
The present study aimed to explore the function of miR-34b promoter methylation in cell proliferation in children's acute leukemia. Quantitative PCR and methylation-specific PCR were performed to measure the levels of miR-34b and its promoter methylation in normal cells, eight leukemia cell lines as well as primary leukemic cells isolated from patients newly diagnosed with acute lymphoblastic leukemia (ALL), acute myeloid leukemia (AML) and mixed lymphocytic lymphoma. miR-34b levels in leukemia cell lines and primary leukemic cells were significantly lower than those in normal cells. The miR-34b promoter was found to be methylated in all leukemia cell lines, 24 of 31 ALL patients and 8 of 19 AML patients, but not in the 23 normal controls. miR-34b expression and methylation of its promoter were not associated with most clinical parameters assessed; however, miR-34b levels in prednisone-sensitive ALL were significantly different from those in insensitive ALL. A cell counting kit- 8 assay showed that transfection of miR-34b mimics into K562 cells inhibited their proliferation. Furthermore, treatment with the demethylating agent 5-aza-2-deoxycytidine significantly enhanced miR-34b expression levels and decreased the methylation status of its promoter in HL-60 and K562 cells. In conclusion, the results of the present study indicated that in pediatric leukemia cells and leukemia cell lines, the expression of miR-34b is inhibited by methylation of its promoter, which impairs the restraining effects of miR-34b on cell proliferation. It was also indicated that the expression of miR-34b in ALL patients may affect their response to early treatments.
\end{abstract}

Correspondence to: Professor Yihuan Chai or Professor Guixiong Gu, Department of Hematology and Oncology, Children's Hospital of Soochow University, 303 Jingde Road, Suzhou, Jiangsu 215003, P.R. China

E-mail: cyh_1949@aliyun.com

E-mail:szggx000@163.com

Key words: acute lymphoblastic leukemia, acute myeloid leukemia, microRNA, DNA methylation, leukemia cell proliferation

\section{Introduction}

Leukemia has the highest incidence rate $(3-4 / 100,000)$ among all types of pediatric cancer (patient age, $<18$ years), and its incidence is increasing (1). In China, 15,000 patients are newly diagnosed with pediatric leukemia each year, of which $>90 \%$ classify as acute leukemia (AL). The development of AL is a complex, multi-step process. Although combined chemotherapy and hematopoietic stem cell transplantation technology have considerably improved the survival rate of patients with pediatric leukemia, the rate of recurrences in locations including the bone marrow, testicles and central nervous system, is $25-30 \%$ (2). Further study of the pathogenesis of leukemia will aid in the discovery of novel treatments and prognostic markers.

For the pasttwodecades, studies on the molecularmechanisms of leukemia have mainly focused on chromosomal abnormalities and protein-coding genes (3). Recently, non-coding microRNAs (miRNA) were found to have promoting or suppressive effects on factors associated with the occurrence, development, clinical manifestation and prognosis of leukemia (4). miRNAs are a class of endogenous, single-stranded, small, non-coding RNA molecules containing 21-25 nucleotides. miRNAs are thought to be generated through a selective amplification mechanism and participate in a broad range of biological processes, including ontogeny, cell differentiation, proliferation, apoptosis, aging and stress (5-7). miRNA-expressing genes are often clustered in fragile chromosome sites or cancer-associated genomic regions (8). Abnormal expression levels of miRNA in tumor cells are associated with tumor occurrence, development and prognosis (9). It is known that miRNA expression is regulated by DNA methylation and other epigenetic factors, which may have a feedback interaction (10). As an important epigenetic phenomenon, DNA methylation activity is frequently deregulated in tumor cells and $\mathrm{CpG}$ island hypermethylation in tumor suppressor genes may silence gene expression (11). Expression of miRNA is also regulated by DNA methylation and other epigenetic factors, among which miRNA itself may also affect DNA methylation. DNA hypermethylation decreases the expression of tumor suppressor miRNAs and increases the expression of oncogenic miRNAs. In addition, histone modifications may also affect the expression of miRNAs and cause tumor formation (12-15). However, the epigenetic regulation of miRNAs in cancer has largely remained elusive. 
miR-34b belongs to the miR-34 family, which comprises miR-34a, -b and -c. In humans, two gene clusters encode miR-34, including the miR-34a gene located on chromosome 1p36 and the miR-34b/c gene located on chromosome 11q23 (16). It has been found that miR-34b is abnormally expressed in a variety of malignant cancers. In colorectal cancer $(5,17,18)$ and gastric cancer $(19,20)$, the $\mathrm{CpG}$ island in the miR-34b promoter region is hypermethylated and the expression of miR-34b is downregulated, which reduces its availability to exert its tumor-suppressive function. In pancreatic cancer, miR-34b functions as a tumor suppressor by targeting oncogene Smad3, and its low expression is positively correlated with the tumor-nodes-metastasis stage, lymph node metastasis and overall survival (21). In p53-depleted human ovarian cancer (22) and epithelial ovarian cancer with p53 point mutation (23), the expression of miR-34b was shown to be downregulated, suggesting that miR-34b can inhibit the proliferation, adhesion and growth of cancer cells. In endometrial serous adenocarcinoma, the $\mathrm{CpG}$ island of the miR-34b promoter region is hypermethylated, which inhibits the expression of miR-34b (24). This phenomenon suggested that miR-34b is able to inhibit the invasion, growth and migration of cancer cells.

While miR-34b has been found to function as a tumor suppressor gene in a variety of solid tumor types (15,17-20), its role in children with acute lymphoblastic leukemia (ALL) has not been reported, to the best of our knowledge. Abnormalities of $11 q 23$, which contains the miR-34b gene (25), are the most common chromosomal variations in certain hematopoietic malignancies, occurring in $60-70 \%$ of children with ALL. Therefore, it is of particular interest to study the roles of miR-34b in regulating the proliferation of leukemic cells and in the pathogenesis of pediatric leukemia. The present study used reverse-transcription quantitative polymerase chain reaction (qRT-PCR) and methylation-specific PCR (MSP) to examine the expression levels and $\mathrm{CpG}$ island methylation status of the miR-34b gene promoter in pediatric ALL and analyze its clinical significance. Furthermore, leukemia cells were treated with 5-aza-2-deoxycytidine (5-aza-2-dC) to examine the effects of miR-34b promoter methylation in leukemia. Furthermore, K562 cells were transfected with miR-34b mimics to evaluate its effects on cell proliferation.

\section{Materials and methods}

Cell lines. The U937 (CRL-2367 $\left.{ }^{\mathrm{TM}}\right)$, HL-60 (CCL-240 ${ }^{\mathrm{TM}}$ ), MV4-11 (CRL-9591 ${ }^{\mathrm{TM}}$ ), M2R (ABT-737 resistant MV4-11), K562 $\left(\right.$ CCL-243 $\left.{ }^{\mathrm{TM}}\right)$ and DAMI (CRL-9792 ${ }^{\mathrm{TM}}$ ) leukemia cell lines were purchased from the American Type Culture Collection (Manassas, VA, USA). The CCRF and Raji leukemia cell lines were a kind gift from Professor Jianrong Wang at Cyrus Tang Blood Hematology Center of Soochow University (Soochow, China). All cells were cultured in RPMI 1640 (Hyclone; GE Healthcare, Little Chalfont, UK) containing 10\% fetal bovine serum (FBS; Hyclone) in a humidified incubator (Midi40; Thermo Fisher Scientific, Waltham, MA, USA) containing 5\% $\mathrm{CO}_{2}$ at $37^{\circ} \mathrm{C}$.

Clinical samples. Bone marrow samples were collected from 87 AL patients at the Blood Center of the Children's Hospital of Soochow University (Suzhou, China) from December 2010 to January 2013. The patients' bone marrow mononuclear cells (BMNCs) were used in the present study, which were isolated using Ficoll solution. Patients were diagnosed with AL using combined analysis of morphology, immunology, cytogenetics and molecular biology (MICM) (26). Leukemic fusion genes, including those for mixed lineage leukemia (MLL), were detected by RT-PCR. A total of 38 male and 17 female patients with a median age of 5 years (range, 0.1-13.6 years) and a median white blood cell (WBC) count of $50.74 \times 10^{9} / 1$ (range, 2.1-638x $\left.10^{9} / 1\right)$ were diagnosed with ALL. Furthermore, 17 male and 15 female patients were diagnosed with acute myeloid leukemia (AML) and had a median age of 6.55 years (range, $0.1-13$ years) and a median WBC count of $43.78 \times 10^{9} / 1$ (range, $\left.1.8-598.9 \times 10^{9} / 1\right)$. In addition, normal bone marrow samples of 29 males and 14 females were collected from the Surgical Department of the Children's Hospital of Soochow University (Suzhou, China) as controls. The median age was 6 years (range, 0.1-16 years) and the median WBC was $7.84 \times 10^{9} / 1$ (2.92-18.63× $\left.10^{9} / 1\right)$. Treatments for AL included chemotherapy and extramedullary leukemia prevention. Patients with ALL were given chemotherapy according to the Children's Cancer \& Leukaemia Group-2008 regimen (27) and AML patients were treated using state-of-the-art generic chemotherapy. The present study was approved by the Ethics Committee of the Children's Hospital of Soochow University (Suzhou, China) and signed informed consent was provided by the patient's parents or guardians. The prednisone sensitivity test was performed according to the Children's Cancer \& Leukemia Group 2008 regimen (27).

5-Aza-2'-deoxycytidine (5-aza-2-dC) treatment. K562 or HL-60 cells were seeded into a six-well plate $\left(1.0-1.5 \times 10^{6}\right.$ cells per well; four well per cell line). $2 \mu 1$ 5-aza-2-dC (FINC Chemical Technology, Shanghai, China) was added into two wells of each cell type. Following incubation for $48 \mathrm{~h}, 1 \mathrm{ml}$ TRIzol (Thermo Fisher Scientific) was added to each well. DNA and RNA were extracted from each group for RT-qPCR and MSP experiments.

$R T-q P C R$. Total RNA was extracted from monocytes with TRIzol according to the manufacturer's instructions. $2 \mu \mathrm{g}$ RNA was used to generate the cDNA library for amplifying target genes. A TaqMan MicroRNA Reverse Transcription kit (Thermo Fisher Scientific) was used to synthesize the cDNA. The reaction mixture contained $0.15 \mu 1100 \mathrm{mM}$ deoxynucleotide triphosphate, $1 \mu \mathrm{l}$ MultiScribe reverse transcriptase, $1.5 \mu \mathrm{l}$ reverse transcription buffer (10X), $0.19 \mu 1$ RNase inhibitor, $4.16 \mu 1$ nuclease-free water, $3 \mu \mathrm{l}$ primer and $5 \mu \mathrm{l}$ RNA. The following conditions were used for reverse transcription: $16^{\circ} \mathrm{C}$ for $30 \mathrm{~min}, 42^{\circ} \mathrm{C}$ for $30 \mathrm{~min}, 80^{\circ} \mathrm{C}$ for $5 \mathrm{~min}$ and $4^{\circ} \mathrm{C}$ for $1 \mathrm{~min}$.

The TaqMan MicroRNA Assay and TaqMan Universal PCR Master Mix (Thermo Fisher Scientific) were used to amplify the cDNA in a LightCycler $480{ }^{\circledR}$ II (Roche, Basel, Switzerland). The reaction contained $1 \mu \mathrm{l}$ TaqMan MicroRNA Assay mixture (20X), $1.3 \mu \mathrm{l}$ cDNA product mixture, $10 \mu \mathrm{l}$ TaqMan Universal PCR Master Mix (2X) and $7.7 \mu 1$ nuclease-free water. FAM ${ }^{\mathrm{TM}}$ dye (GenePharma, Shanghai, China) was added as the fluorescence probe. PCR was performed using the following cycling conditions with incorporation of FAM into the nucleotides: $95^{\circ} \mathrm{C}$ for $10 \mathrm{~min}$, followed by 55 cycles of $95^{\circ} \mathrm{C}$ for $15 \mathrm{sec}$ and $60^{\circ} \mathrm{C}$ for $60 \mathrm{sec}$. U6 small nuclear (sn)RNA (5'-GTGCTCGCT 
TCGGCAGCACATATACTAAAATTGGAACGATACAGA GAAGATTAGCATGGCCCCTGCGCAAGGATGACA CGCAAATTCGTGAAGCGTTCCATATTTT-3') was used as an internal control to normalize the relative repression levels of miR-34b mimics (5'-UAGGCAGUGUCAUUAGCUGAU UG-3'). Melting curve analysis was performed and the R-value was calculated from the difference between the target gene in the experimental group compared to that of the control group, using the $2^{-\Delta \Delta \mathrm{Ct}}$ method where $\mathrm{Ct}$ was the cycle threshold (i.e., the cycle number at which the fluorescence reached the set threshold). $\Delta \mathrm{Ct}$ was calculated by subtracting the $\mathrm{Ct}$ value of the U6 snRNA reference from the $\mathrm{Ct}$ value of miR-34b mimics: $\Delta \mathrm{Ct}_{\text {miR-34b }}=\mathrm{Ct}_{\text {miR-34b }}-\mathrm{Ct}_{\mathrm{U} 6 \text { snRNA }} . \Delta \Delta \mathrm{Ct}$ was then calculated by subtracting the $\Delta \mathrm{Ct}$ of the respective sample from the $\Delta \mathrm{Ct}$ of the control group: $\Delta \Delta \mathrm{Ct}=\Delta \mathrm{Ct}_{\mathrm{Sample}}-\Delta \mathrm{Ct}_{\mathrm{Control}}$. Triplicate experiments were performed for each sample.

The primers used for PCR amplification were as follows: miR-34b forward, 5'-TGGTTTAGTTATGTGTGTTGTGT-3' and reverse, 5'-CAACTACAACTCCCA AACAATCC-3' (Invitrogen; Thermo Fisher Scientific).

Genomic DNA isolation and MSP. The TIANamp Genomic DNA kit (Tiangen, Beijing, China) was used to extract the genomic DNA from cell lines and monocytes according to the manufacturer's instructions. Briefly, cells were centrifuged at $400 \mathrm{x}$ g for $5 \mathrm{~min} .200 \mu \mathrm{l} \mathrm{GA}$ buffer was added after removing the supernatant. After proteinase $\mathrm{K}$ treatment, $200 \mu \mathrm{l} \mathrm{GB}$ buffer was added followed by incubation at $70^{\circ} \mathrm{C}$ for $10 \mathrm{~min}$. $200 \mu \mathrm{l}$ ethanol was then added and DNA was purified using the column included in the kit. The DNA concentration was measured with a BioMate ${ }^{\mathrm{TM}} 35$ ultraviolet spectrophotometer (Chemlab Corp., Shanghai, China). The EZ Methylation-Gold kit (Zymo Research, Irvine, CA, USA) was used to modify the genomic DNA with sodium bisulfite according to the manufacturer's instructions. Conversion Reagent was prepared by adding $900 \mu \mathrm{l}$ water, $50 \mu \mathrm{l}$ M-Dissolving Buffer and $300 \mu \mathrm{l}$ M-Dilution Buffer into a tube of CT Conversion Reagent supplied with the kit. $130 \mu \mathrm{l}$ CT Conversion Reagent was mixed with $20 \mu \mathrm{l}$ genomic DNA and reacted for $10 \mathrm{~min}$ at $98^{\circ} \mathrm{C}$, followed by $2.5 \mathrm{~h}$ at $64^{\circ} \mathrm{C} .600 \mu \mathrm{l}$ M-Binding Buffer was mixed with DNA sample in a Zymo-Spin IC Column (Zymo Research). After centrifugation at $400 \mathrm{x}$ g for $10 \mathrm{sec}, 200 \mu \mathrm{l}$ M-Desulphonation Buffer was added onto the same column following incubation for 15-20 min at room temperature. The column was then washed twice with M-Wash buffer. 10-20 $\mu 1$ M-Elution Buffer was used to elute the modified genomic DNA. Takara Taq ${ }^{\mathrm{TM}}$ (Takara Bio, Inc., Otsu, Japan) was used for methylation-specific PCR. The sequences of the primers were as follows (12): Methylated miR-34b forward, 5'-TTT AGTTACGCGTGTTGTGC-3' and reverse, 5'-ACTACAACT CCCGAACGATC-3'; unmethylated miR-34b forward, 5'-TGG TTTAGTTATGTGTGTTGTGT-3' and reverse, 5'-CAACTA CAACTCCCAAACAATCC-3'.

Cell transfection. Transfection was performed using Lipofectamine 2000 (Thermo Fisher Scientific) according to the manufacturer's instructions. In brief, $4 \times 10^{5} \mathrm{~K} 562$ cells were cultured in $2 \mathrm{ml}$ antibiotic-free RPMI 1640 medium containing $10 \%$ FBS in a six-well plate one day prior to transfection. $24 \mu \mathrm{l}$ Homo sapiens (hsa)-miR34b mimics and $24 \mu \mathrm{l}$ negative control (GenePharma) were mixed with $226 \mu$ l Opti-MEM (Invitrogen), respectively. $12 \mu \mathrm{l}$ Lipofectamine 2000 was mixed with $238 \mu$ l Opti-MEM and then mixed with the hsa-miR-34b mimics- or negative control-Opti-MEM solution. After incubation for $20 \mathrm{~min}$ at room temperature, the mixtures were added drop-wise to the cultured cells. Culture medium was replaced 4-6 $\mathrm{h}$ after transfection. Each transfection was performed in three replicates. The sequences of the FAM-labeled miRNAs were as follows: hsa-miR-34b mimics sense, 5'-CAAUCACUA ACUCCACUGCCAU-3' and anti-sense, 5'-GGCAGUGGA GUUAGUGAUUGUU-3'; negative control sense, 5'-UUCUCC GAACGUGUCACGUTT-3' and anti-sense, 5'-ACGUGACAC GUUCGGAGAATT-3'.

Flow cytometry. Cells were harvested 48 h after transfection. Following two washes with phosphate-buffered saline, cells were re-suspended in $600 \mu \mathrm{l}$ phosphate-buffered saline and analyzed on a FACScan flow cytometer (BD Biosciences, San Jose, CA, USA). Data were analyzed using CellQuest Pro 5.2 software (BD Biosciences).

Cell Counting Kit-8 (CCK-8) proliferation assay. After transfection, cells in the exponential phase were collected in RPMI 1640 medium containing 10\% FBS. Cell suspension (200 $\mu \mathrm{l})$ was added into each well of five 96-well plates at a concentration of $2.5 \times 10^{4} / \mathrm{ml}$. Cells were analyzed at the time-points of 24, 48, 72, 96 and $120 \mathrm{~h}$. Five replicates of the blank control, negative control, experimental group and culture medium control were assessed at each time-point. $20 \mu \mathrm{l}$ CCK-8 (Shanghai Yes Service Biotech, Shanghai, China) was added into each well and cells were incubated for another $2 \mathrm{~h}$. The optical density at $450 \mathrm{~nm}\left(\mathrm{OD}_{450}\right)$ was then assessed using a microplate reader (MultiSkan FC, Thermo Fisher Scientific) and regarded as a measure of the number of viable cells.

Statistical analysis. All statistical analyses were performed using SPSS version 17.0 software (SPSS, Inc., Chicago, IL, USA). Values are expressed as the mean \pm standard deviation. Student's t-test was used for comparisons among multiple groups. $\mathrm{P}<0.05$ was considered to indicate a statistically significant difference.

\section{Results}

miR-34b is downregulated in leukemia cells. First, RT-qPCR analysis was performed to compare the expression levels of miR-34b between 8 leukemia cell lines as well as the BMNCs of 42 ALL patients, 20 AML patients, 11 patients with MLL and 20 age-matched normal individuals. Compared with that in normal controls $(5.22 \pm 1.15)$, the relative expression of miR-34b in leukemia cell lines $(0.03 \pm 0.03$; $\mathrm{P}<0.01)$ as well as in BMNCs cells of patients with ALL $(1.65 \pm 0.69 ; \mathrm{P}<0.05)$, AML $(0.18 \pm 0.06 ; \mathrm{P}<0.01)$ and $\operatorname{MLL}(0.64 \pm 0.34 ; \mathrm{P}<0.01)$ was significantly downregulated (Table I, Fig. 1). This result indicated that miR-34b may represent a diagnostic indicator for leukemia. To further evaluate the potential of using miR-34b as a clinical marker for AL, miR-34 expression in AL patients was compared with their clinical parameters. However, no correlation between the expression levels of miR-34 and 
Table I. Relative expression of miR-34b in different groups.

\begin{tabular}{lccr}
\hline Group & Cases (n) & Relative expression & P-value \\
\hline Normal & 20 & $5.22 \pm 1.15$ & - \\
Cell lines & 8 & $0.03 \pm 0.03$ & $<0.001$ \\
ALL & 42 & $1.65 \pm 0.69$ & 0.012 \\
AML & 20 & $0.18 \pm 0.06$ & $<0.001$ \\
MLL+ & 11 & $0.64 \pm 0.34$ & 0.001 \\
\hline
\end{tabular}

Values are expressed as the mean \pm standard deviation. P-values refer to comparison with control group. Cell lines comprise U937, HL-60, MV4-11, M2R, K562, Raji, CCRF and DAMI. MLL+, AL patients with mixed lineage leukemia rearrangement; ALL, acute lymphoblastic leukemia; AML, acute myeloid leukemia.

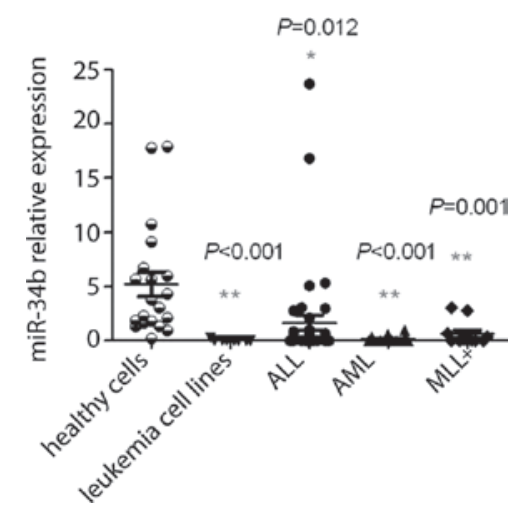

Figure 1. Expression of miR-34b in leukemia cells. Histogram showing the relative levels of miR-34b in healthy cells, leukemia cell lines, ALL cells, AML cells and MLL+ cells. Compared with normal cells, the levels of miR-34b in leukemia cell lines, ALL cells, AML cells, and MLL+ cells were significantly lower $(\mathrm{P}<0.05)$. MLL+ indicates AL patients with MLL rearrangement. Leukemia cell lines comprised U937, HL-60, MV4-11, M2R, K562, Raji, CCRF and DAMI. Each data point represents the result for one subject/cell line, horizontal bars represent the mean value and bars indicate the standard deviation. ${ }^{*} \mathrm{P}<0.05 ;{ }^{* *} \mathrm{P}<0.01$ vs. healthy cells. miR, microRNA; ALL, acute lymphoblastic leukemia; AML, acute myeloid leukemia; MLL, mixed lineage leukemia.

the patients' gender, age, WBC number, immunophenotype, karyotype, gene fusion, MLL gene rearrangement or LDH levels were identified $(\mathrm{P}>0.05)$ (Table II). Of note, the expression levels of miR-34b in patients sensitive to the ALL prednisone reaction $(0.67 \pm 0.22)$ were significantly lower than those in insensitive patients $(4.40 \pm 2.45 ; \mathrm{P}=0.015)$ (Table II).

miR-34b inhibits leukemia-cell proliferation. To assess the effects of miR-34b on cell proliferation, hsa-miR-34b mimics and negative control RNA were transfected into K562 cells. The transfection efficiency of hsa-miR-34b in K562 cells was $61 \%$, as determined by flow cytometry (Fig. 2A). K562-cell proliferation was then evaluated using the CCK- 8 cell proliferation assay. The $\mathrm{OD}_{450}$-values of hsa-miR-34b-transfected cells were significantly lower than those of non-transfected cells or negative control-transfected cells at $48 \mathrm{~h}, 72 \mathrm{~h}, 96 \mathrm{~h}$ and $120 \mathrm{~h}(\mathrm{P}<0.01)$ (Fig. 2B). At $72 \mathrm{~h}$, cell proliferation was inhibited by $45.7 \%$ in hsa-miR-34b mimic-transfected cells as compared with that in negative control cells (Fig. 2B).
A

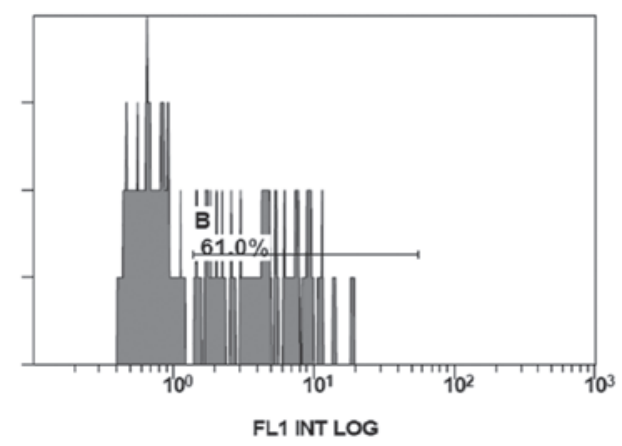

B

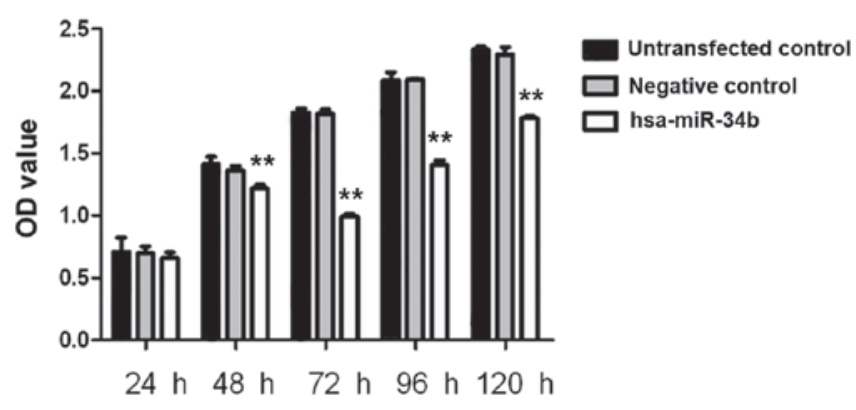

Figure 2. Expression of miR-34b reduces the proliferation of K562 cells. (A) Flow cytometry histogram showing that the transfection efficiency of miR-34b in K562 cells was $\sim 61 \%$. (B) Histogram showing the average cell proliferation rate of untransfected, negative control and hsa-miR34b-transfected cells at 24, 48, 72, 96 and $120 \mathrm{~h}$. Values are expressed as the mean \pm standard deviation. ${ }^{* *} \mathrm{P}<0.01$ vs. control. miR, microRNA; hsa, Homo sapiens; OD, optical density; Int, intensity.

miR-34b expression is regulated via methylation of $C p G$ islands in its gene promoter. To examine whether the methylation of $\mathrm{CpG}$ island in the promoter of miR-34b is involved in the regulation of its expression, MSP analysis was performed to detect the methylation status of $\mathrm{CpG}$ islands in leukemia cell lines as well as in BMNCs from ALL patients, AML patients MLL patients and healthy controls. No methylation was detected in cells from all 23 normal control subjects (results from 13 controls are shown in Fig. 3A). However, methylation was present in the miR-34b gene promoters of all leukemia cell lines (U937, HL-60, MV4-11, M2R, K562, Raji, CCRF and DAMI) (Fig. 3B). Among the 31 ALL patients, methylation was detected in 24 patients (results from 15 patients are shown in Fig. 3C). Among the 19 AML patients, methylation was detected in eight patients (results from nine patients are shown in Fig. 3D). The methylation status was then assessed in all acute leukemia patients. Similarly, no correlation was found between methylation and patients' gender, age, karyotype, gene fusion, MLL gene rearrangement, TEL/AML1 gene, Hb number, WBC count, platelet count or LDH levels ( $\mathrm{P}>0.05)$ (Table III). However, a significant difference in miR-34b promoter methylation was detected between patients with ALL and those with AML ( $\mathrm{P}=0.012)$ (Table III). Thus, the methylation status of the miR-34b promoter may be utilized as a marker for the diagnosis of leukemia sub-types.

5-Aza-2-dC treatment increases the expression of $\mathrm{miR}-34 \mathrm{~b}$ and decreases the methylation of its promoter. To evaluate the 
Table II. Association between miR-34b expression levels and clinical parameters of patients newly diagnosed with AL.

\begin{tabular}{|c|c|c|c|}
\hline Clinical parameter & Number & Relative miR-34b expression level & P-value \\
\hline Gender & & & 0.684 \\
\hline Male & 36 & $1.01 \pm 0.49$ & \\
\hline Female & 26 & $1.41 \pm 0.92$ & \\
\hline Age (years) & & & 0.797 \\
\hline$<1$ & 7 & $0.50 \pm 0.43$ & \\
\hline $1-10$ & 49 & $1.34 \pm 0.59$ & \\
\hline$>10$ & 6 & $0.60 \pm 0.32$ & \\
\hline WBC count $\left(10^{9} / 1\right)$ & & & 0.166 \\
\hline$<50$ & 28 & $2.16 \pm 1.02$ & \\
\hline $50-100$ & 9 & $0.69 \pm 0.28$ & \\
\hline$>100$ & 25 & $0.48 \pm 1.75$ & \\
\hline Immunosubtype & & & 0.115 \\
\hline Lymphoid & 42 & $1.65 \pm 0.69$ & \\
\hline Myeloid & 20 & $0.18 \pm 0.06$ & \\
\hline Karyotype & & & 0.740 \\
\hline Normal & 29 & $1.35 \pm 0.82$ & \\
\hline Abnormal & 33 & $1.03 \pm 0.53$ & \\
\hline Gene fusion & & & 0.209 \\
\hline Undetectable & 26 & $1.88 \pm 1.10$ & \\
\hline Abnormal & 36 & $0.67 \pm 0.20$ & \\
\hline MLL gene rearrangement & & & 0.603 \\
\hline Negative & 51 & $1.29 \pm 0.57$ & \\
\hline Positive & 11 & $0.64 \pm 0.34$ & \\
\hline LDH levels & & & 0.265 \\
\hline$<500 \mathrm{U} / 1$ & 17 & $2.04 \pm 1.39$ & \\
\hline$\geq 500 \mathrm{U} / 1$ & 45 & $0.85 \pm 0.39$ & \\
\hline ALL prednisone reaction & & & 0.015 \\
\hline Sensitive & 31 & $0.67 \pm 0.22$ & \\
\hline Insensitive & 11 & $4.40 \pm 2.45$ & \\
\hline
\end{tabular}

Expression levels are presented as the mean \pm standard deviation relative to U6 small nuclear RNA. miR, microRNA, ALL, acute lymphoblastic leukemia; WBC, white blood cell; MLL, mixed lymphocytic lymphoma; LDH, lactate dehydrogenase.

association between the expression levels and the $\mathrm{CpG}$ island methylation status of the miR-34b gene promoter, HL-60 and K562 cells were treated with the demethylating agent 5-aza-2-dC. Methylation of the promoter of miR-34b was obviously decreased by 5-aza-2-dC (Fig. 4A). Furthermore, miR-34b expression in 5-aza-2-dC-treated HL-60 and K562 cells was 49.5- and 18.8-fold increased, respectively, compared with that in untreated cells (Fig. 4B).

\section{Discussion}

In order to study the function of miR-34b and the methylation of its promoter in AL, the expression levels of miR-34b were assessed in a panel of leukemia cell lines as well as in leukemia cells from young patients with various types of AL and healthy control subjects using RT-qPCR. Compared with that in normal control subjects, the expression of miR-34b in leukemia cell lines and leukemia cells of patients with ALL,
AML or MLL was significantly decreased, which is consistent with the findings of previous studies $(28,29)$. Therefore, it was indicated that miR-34b is a tumor suppressor gene, which has a role in the oncogenesis and prognosis of pediatric AL, particularly in MLL. The MLL gene is located on chromosome 11q23 in the same locus that encodes miR-34b. The 11q23/MLL rearrangement has been identified as a specific characteristic of leukemia due to its association with the leukemia type and poor prognosis; furthermore, the selection of an individualized treatment strategy is dependent on the presence of this rearrangement (30). The World Health Organization has classified the 11q23 rearrangement separately as '11q23/MLL leukemia' (31). Munoz et al (30) reported that patients with MLL-gene rearrangement were insensitive to conventional chemotherapy, but responded to high-dose chemotherapy or stem-cell transplantation. Thus, detection of miR-34b may assist in the selection of a patient's chemotherapy regimen. 
Table III. Association between miR-34b methylation and clinical parameters of patients newly diagnosed with acute leukemia.

miR-34b methylation status

Clinical parameter

Methylated $(\mathrm{n}=32) \quad$ Non-methylated $(\mathrm{n}=18)$

P-value

Gender

Male

Female

Immunosubtype

Lymphoid

Myeloid

Karyotype

Normal

Abnormal

Gene fusion

Undetectable

Abnormal

MLL gene rearrangement

Positive

Negative

$21(65.6 \%)$

$11(34.4 \%)$

$24(75.0 \%)$

$8(25 \%)$

$15(46.9 \%)$

$17(53.1 \%)$

$14(43.8 \%)$

$18(56.2 \%)$

$3(9.4 \%)$

$29(90.6 \%)$

TEL/AML1 gene

Positive

Negative

Age (years)

Hemoglobin (g/l)

WBC count $\left(10^{9} / 1\right)$

Platelet count $\left(10^{9} / 1\right)$

LDH levels (U/1)

$3(9.4 \%)$
$29(90.6 \%)$
$6.26 \pm 3.29$
$76.81 \pm 25.30$
$113.40 \pm 163.57$
$46.22 \pm 39.45$
$2038.84 \pm 3921.65$

0.631

$7(38.9 \%)$

$11(61.1 \%)$

$7(38.9 \%)$

$11(61.1 \%)$

$10(55.6 \%)$

$8(44.4 \%)$

0.292

$0(0 \%)$

$18(100 \%)$

0.402

$4(22.2 \%)$

$14(77.8 \%)$

$6.67 \pm 3.47$

0.685

$80.61 \pm 21.86$

0.596

$92.15 \pm 162.15 \quad 0.660$

$\begin{array}{ll}47.67 \pm 33.73 & 0.896\end{array}$

$\begin{array}{ll}1517.45 \pm 1771.48 & 0.597\end{array}$

Values are presented as the mean \pm standard deviation. miR, microRNA, WBC, white blood cell; MLL, mixed lineage leukemia; LDH, lactate dehydrogenase.

A

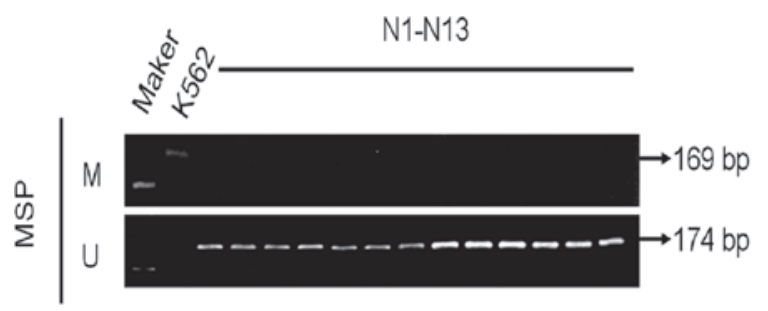

C

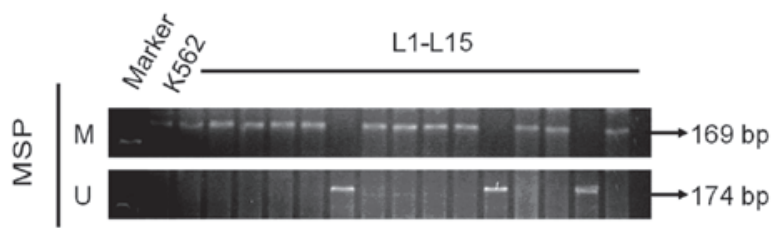

B

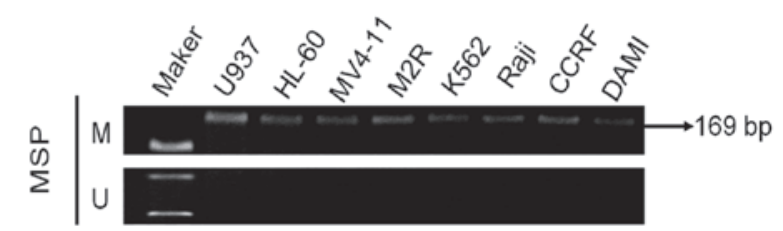

D

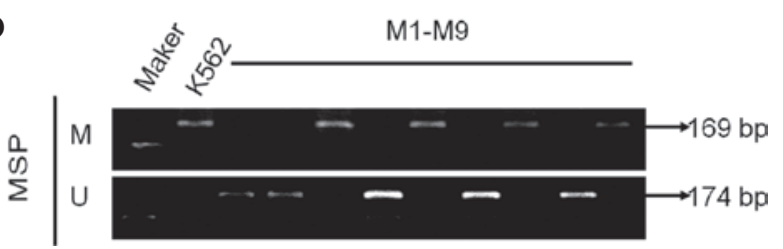

Figure 3. miR-34b is exclusively methylated in leukemia cells. An MSP assay revealed that (A) miR-34b was unmethylated in normal cells, (B) miR-34b was methylated in eight leukemia cell lines comprising U937, HL-60, MV4-11, M2R, K562, Raji, CCRF and DAMI. (C) miR-34b was methylated in the majority (24 out of 31) of the acute lymphoblastic leukemia cell samples (results from 15 patients are shown). (D) miR-34b was methylated in several acute myeloid leukemia cell samples (8 out of 19; results for nine patients are shown). miR, microRNA; M, methylated; U, unmethylated; MSP, A methylation-specific polymerase chain reaction.

The present study also analyzed the association between miR-34b expression levels and clinical characteristics of patients diagnosed with AL. No significant difference between the relative expression of miR-34b and gender, age, initial WBC count, immunophenotype, chromosome fusion, MLL gene rearrangements, LDH levels at diagnosis 
A

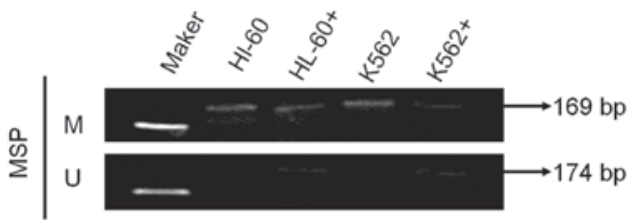

B

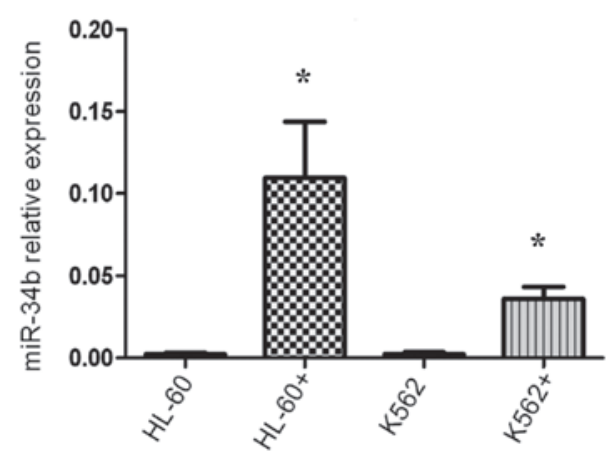

Figure 4. 5-Aza-2-dC treatment decreases the methylation and expression of miR-34b in HL-60 and K562 cells. (A) An MSP assay revealed methylation of miR-34b in HL-60 and K562 cells prior to 5-aza-2-dC treatment and decreased miR-34b levels after 5-aza-2-dC treatment. (B) Histogram showing the expression of miR-34b in HL-60 and K562 cells prior to and after 5 -aza-2-dC treatment. Values are presented as the mean \pm standard deviation. ${ }^{*} \mathrm{P}<0.05$ vs. HL-60. +, experiments with 5 -aza-2-dC treatment; miR, microRNA; M, methylated; U, unmethylated; MSP, A methylation-specific polymerase chain reaction; 5-aza-2-dC, 5-aza-2-deoxycytidine.

or other indicators were identified $(\mathrm{P}>0.05)$. Of note, the relative expression levels of MiR-34b in MLL patients were decreased compared with those in patients with non-MLL leukemia; however, this difference was not statistically significant, presumably due to the limited number of specimens. The prednisone test, which reflects the early treatment response, is able to predict the prognosis of ALL (32). In the present study, the relative expression of miR-34b was significantly different between ALL patients who were sensitive to the prednisone test and prednisone-insensitive patients $(\mathrm{P}<0.05)$, indicating that the relative expression of miR-34b may affect the early treatment response and may also serve as an indicator of poor prognosis newly diagnosed ALL patients.

Abnormalities in DNA methylation and aberrant expression of miRNAs were found to have an important role in the occurrence, development and prognosis of leukemia (33). The $\mathrm{CpG}$ island of the miR-34b promoter was found to be hypermethylated and miR-34b expression was downregulated in a variety of solid tumor types $(15,17-20)$ as well as in hematological malignancies $(28,29,33,34)$. Leucci et al $(34)$ reported that the $\mathrm{CpG}$ island of the miR-34b promoter was hypermethylated and that miR-34b was silenced in Burkitt's lymphoma without MYC translocation. Pigazzi et al (28) reported that the miR-34b promoter in leukemia cell lines was also hypermethylated. Recently, Pigazzi et al (29) found that miR-34b expression was decreased in patients newly diagnosed with $\mathrm{AML}$, and that the miR-34b promoter was hypermethylated in $66 \%$ of AML patients. However, to the best of our knowledge, methylation of the miR-34b promoter in patients newly diagnosed with ALL has not been reported. The present study used MSP to detect miR-34b promoter methylation in patients newly diagnosed with AL and found that methylation was present in all of the eight leukemia cell lines assessed (U937, HL-60, MV4-11, M2R, K562, Raji, CCRF and DAMI), in 24 out of 31 patients (77.42\%) newly diagnosed with ALL, and in 8 out of 19 patients (42.11\%) newly diagnosed with AML. However, no hypermethylation was detected in the 23 normal control subjects, suggesting that methylation of the miR-34b promoter is closely associated with hematopoietic malignances. The present study also found that the percentage of miR-34b promoter hypermethylation in patients newly diagnosed with ALL was significantly higher than that in patients newly diagnosed with AML. Pigazzi et al (29) reported that the miR-34b promoter was hypermethylated in $66 \%$ of AML patients, which is higher than the ratio determined in the present study. This difference may be due to the differences in ethnic groups or the small cohort size.

Pigazzi et al (29) reported that the miR-34b promoter methylation status in patients newly diagnosed with AML was not correlated with their clinical parameters, but was associated with poor prognosis and a lower overall survival. Consistently, the results of the present study indicated no significant difference between methylation status and relevant clinical parameters, including the patient's gender, age, chromosome fusion, TEL/AML1 gene expression, initial hemoglobin count, WBC count, platelet count and LDH levels, in patients newly diagnosed with AL $(\mathrm{P}>0.05)$. However, the present study found that the miR-34b promoter methylation level in lymphoid leukemia was significantly different from that in myeloid leukemia $(\mathrm{P}<0.05)$. As patients with lymphoid leukemia have a higher remission rate and a longer survival period than those with myeloid leukemia, it may be deduced that miR-34b methylation is correlated with prognosis and overall survival rate.

Methyltransferase inhibitors, such as 5 -aza-2dC, can restore the expression of methylation-silenced genes (35). In this study, 5-aza-2-dC treatment was shown to inhibit the methylation of the miR-34b promoter and increase the expression of miR-34b. CpG island hypermethylation of tumor suppressor gene promoters is a common phenomenon in human leukemia (36). The present study confirmed that $\mathrm{CpG}$ island hypermethylation reduced the expression of the tumor suppressor miRNA miR-34b, which was regulated via $\mathrm{CpG}$ island methylation in leukemia cell lines and patient samples.

To further assess the suppressive effects of miR-34b on leukemia-cell proliferation, hsa-miR-34b mimics were transfected into the K562 leukemia cell line. A CCK-8 assay revealed that high expression of miR-34b led to the suppression of cell proliferation, with $72 \mathrm{~h}$ being the most effective time-point leading to a decrease of K562-cell proliferation by almost $50 \%$ compared with that of non-transfected or control-transfected K562 cells. Pigazzi et al (28) transfected miR-34b into HL-60 and K562 cells and also found that cell growth and proliferation were inhibited, and that the cell populations in the S-phase and $\mathrm{G} 2 / \mathrm{M}$ phase of the cell cycle were significantly reduced, indicating that miR-34b inhibits leukemia-cell proliferation by causing cell-cycle arrest. The same group also inoculated miR-34b-transfected HL-60 and K562 cells into NOD-SCID interleukin-2 receptor gamma-null mice, which resulted in the formation of obviously smaller tumors compared with those generated from empty vector-transfected cells, further confirming the role of miR-34b as a tumor suppressor gene 
in vivo (30). The results of the present study are consistent with these two studies, suggesting that miR-34b also has a tumor suppressor role in pediatric leukemia.

In conclusion, the results of the present study suggested that miR-34b promoter methylation is likely to be an important post-transcriptional regulatory mechanism associated with childhood leukemia. This finding may aid in the development of novel diagnostic methods and therapies for childhood leukemia.

\section{Acknowledgements}

The present study was supported by the National 'Eleventh Five-Year' Major Science and Technology Funding grant (no. 2007BAI04B03), the National 'Twelfth Five-Year' Major Science and Technology Funding grant (no. 2011ZX09302-007-01), the National Natural Science Foundation of China (no. 81100371), the Suzhou Science and Technology Development Plan 2013 (no. SYS201352) and the 2012 Suzhou City 'Science and Education Guardian' Youth Science and Technology Project (no. KJXW2012021).

\section{References}

1. Wang WP: Pediatrics. 8th edition. People's Medical Publishing House, Beijing, 376-383, 2008 (In Chinese).

2. Pui CH: Recent research advances in childhood acute lymphoblastic leukemia. J Formos Med Assoc 109: 777-787, 2010.

3. Gill Super HJ: A role for epigenetics in the formation of chromosome translocations in acute leukemia. Cancer Genet 208: 230-236, 2015.

4. Mourelatos Z, Dostie J, Paushkin S, Sharma A, Charroux B Abel L, Rappsilber J, Mann M and Dreyfuss G: miRNPs: A nove class of ribonucleoproteins containing numerous microRNAs. Genes Dev 16: 720-728, 2002.

5. Alvarez-Garcia I and Miska EA: MicroRNA functions in animal development and human disease. Development 132: 4653-4662, 2005.

6. Doench JG, Petersen CP and Sharp PA: siRNAs can function as miRNAs. Genes Dev 17: 438-442, 2003.

7. He L and Hannon GJ: MicroRNAs: Small RNAs with a big role in gene regulation. Nat Rev Genet 5: 522-531, 2004.

8. Calin GA and Croce CM: MicroRNAs and chromosomal abnormalities in cancer cells. Oncogene 25: 6202-6210, 2006.

9. Gong JN, Yu J, Lin HS, et al: The role, mechanism and potentially therapeutic application of microRNA-29 family in acute myeloid leukemia. Cell Death Differ 21: 100-112, 2014.

10. Moarii M, Boeva V, Vert JP and Reyal F: Changes in correlation between promoter methylation and gene expression in cancer. BMC Genomics 16: 873, 2015.

11. Zhang YY, Tian WP and Mei M: Interaction between miR-21 and DNA methylation in different breast cancer cells. Chin J Appl Physiol 31: 220-224, 2015 (In Chinese).

12. Garzia L, Andolfo I, Cusanelli E, Marino N, Petrosino G, De Martino D, Esposito V, Galeone A, Navas L, Esposito S, et al: MicroRNA-199b-5p impairs cancer stem cells through negative regulation of HES1 in medulloblastoma. PloS One 4: e4998, 2009.

13. Lee KH, Lotterman C, Karikari C, Omura N, Feldmann G, Habbe N, Goggins MG, Mendell JT and Maitra A: Epigenetic silencing of MicroRNA miR-107 regulates cyclin-dependent kinase 6 expression in pancreatic cancer. Pancreatology 9: 293-301, 2009.

14. Noonan EJ, Place RF, Pookot D, Basak S, Whitson JM, Hirata H, Giardina C and Dahiya R: miR-449a targets HDAC-1 and induces growth arrest in prostate cancer. Oncogene 28: 1714-1724, 2009.

15. Toyota M, Suzuki H, Sasaki Y, Maruyama R, Imai K, Shinomura $\mathrm{Y}$ and Tokino T: Epigenetic silencing of microRNA-34b/c and B-cell translocation gene 4 is associated with $\mathrm{CpG}$ island methylation in colorectal cancer. Cancer Res 68: 4123-4132, 2008.
16. He X, He L and Hannon GJ: The guardian's little helper: MicroRNAs in the p53 tumor suppressor network. Cancer Res 67: 11099-11101, 2007.

17. Kalimutho M, Di Cecilia S, Del Vecchio Blanco G, et al: Epigenetically silenced $\mathrm{miR}-34 \mathrm{~b} / \mathrm{c}$ as a novel faecal-based screening marker for colorectal cancer. Br J Cancer 104: 1770-1778, 2011.

18. Lujambio A, Calin GA, Villanueva A, Ropero S, Sánchez-Céspedes M, Blanco D, Montuenga LM, Rossi S, Nicoloso MS, Faller WJ, et al: A microRNA DNA methylation signature for human cancer metastasis. Proc Natl Acad Sci USA 105: 13556-13561, 2008.

19. Suzuki H, Yamamoto E, Nojima M, Kai M, Yamano HO, Yoshikawa K, Kimura T, Kudo T, Harada E, Sugai T, et al: Methylation-associated silencing of microRNA-34b/c in gastric cancer and its involvement in an epigenetic field defect. Carcinogenesis 31: 2066-2073, 2010.

20. Tsai KW, Wu CW, Hu LY, Li SC, Liao YL, Lai CH, Kao HW, Fang WL, Huang KH, Chan WC and Lin WC: Epigenetic regulation of miR-34b and miR-129 expression in gastric cancer. Int $\mathrm{J}$ Cancer 129: 2600-2610, 2011.

21. Liu C, Cheng H, Shi S, Cui X, Yang J, Chen L, Cen P, Cai X, Lu Y, Wu C, et al: MicroRNA-34b inhibits pancreatic cancer metastasis through repressing Smad3. Curr Mol Med 13: 467-478, 2013.

22. Kruse JP and Gu W: Modes of p53 regulation. Cell 137: 609-622, 2009.

23. Teodoro JG, Parker AE, Zhu X and Green MR: p53-mediated inhibition of angiogenesis through up-regulation of a collagen prolyl hydroxylase. Science 313: 968-971, 2006.

24. Feng $\mathrm{Z}$ and Levine AJ: The regulation of energy metabolism and the IGF-1/mTOR pathways by the p53 protein. Trends Cell Biol 20: 427-434, 2010.

25. Raver-Shapira N, Marciano E, Meiri E, Spector Y, Rosenfeld N, Moskovits N, Bentwich Z and Oren M: Transcriptional activation of miR-34a contributes to p53-mediated apoptosis. Mol Cell 26: 731-743, 2007.

26. Xiao R and Zhang R: Combined analysis on morphology, immunology, cytogenetics and molecular biology (MICM) classification of 55 patients with acute promyelocytic leukemia. J Exp Hematol 12: 147-150, 2004 (In Chinese).

27. Gao C, Zhao XX, Li WJ, Cui L, Zhao W, Liu SG, Yue ZX, Jiao Y, Wu MY and Li ZG: Clinical features, early treatment responses and outcomes of pediatric acute lymphoblastic leukemia in China with or without specific fusion transcripts: A single institutional study of 1,004 patients. Am J Hematol 87: 1022-1027, 2012.

28. Pigazzi M, Manara E, Baron E and Basso G: MiR-34b targets cyclic AMP-responsive element binding protein in acute myeloid leukemia. Cancer Res 69: 2471-2478, 2009.

29. Pigazzi M, Manara E, Bresolin S, Tregnago C, Beghin A, Baron E, Giarin E, Cho EC, Masetti R, Rao DS, et al: MicroRNA-34b promoter hypermethylation induces CREB overexpression and contributes to myeloid transformation. Haematologica 98: 602-610, 2013.

30. Munoz L, Nomdedéu JF, Villamor N, Guardia R, Colomer D, Ribera JM, Torres JP, Berlanga JJ, Fernández C, Llorente A, et al: Acute myeloid leukemia with MLL rearrangements: Clinicobiological features, prognostic impact and value of flow cytometry in the detection of residual leukemic cells. Leukemia 17: 76-82, 2003.

31. Cox MC, Panetta P, Venditti A, Del Poeta G, Maurillo L, Tamburini A, Del Principe MI and Amadori S: Fluorescence in situ hybridization and conventional cytogenetics for the diagnosis of 11q23+/MLL+ translocation in leukaemia. Br J Haematol 121: 953-955, 2003.

32. Inaba $\mathrm{H}$ and Pui $\mathrm{CH}$ : Glucocorticoid use in acute lymphoblastic leukaemia. Lancet Oncol 11: 1096-1106, 2010.

33. Wang LQ and Chim CS: DNA methylation of tumor-suppressor miRNA genes in chronic lymphocytic leukemia. Epigenomics 7: 461-473, 2015.

34. Leucci E, Cocco M, Onnis A, De Falco G, van Cleef P, Bellan C, van Rijk A, Nyagol J, Byakika B, Lazzi S, et al: MYC translocation-negative classical Burkitt lymphoma cases: An alternative pathogenetic mechanism involving miRNA deregulation. J Pathol 216: 440-450, 2008.

35. Baylin SB, Herman JG, Graff JR, Vertino PM and Issa JP: Alterations in DNA methylation: A fundamental aspect of neoplasia. Adv Cancer Res 72: 141-196, 1998.

36. Cahill N and Rosenquist R: Uncovering the DNA methylome in chronic lymphocytic leukemia. Epigenetics 8: 138-148, 2013. 